\title{
A Major Difference between the Formation of English Words and the Formation of Chinese Words in Modern Times
}

\author{
Bianye Li \\ George Brown College, Canada
}

\begin{abstract}
The English language is a language of "fertility" due to its continuous formation of new words in modern times. However, the Chinese language is "infertile" because it has basically stopped creating totally new words. The general trend in the development of a Chinese character in the Chinese history has been moving from complexity to simplicity. As a result, it leads to the "infertility" of the Chinese language and makes it difficult to combine a limited number of different strokes within a limited space known as 方块字 Fängkuàizì 'Square Block Word'. What is a totally new word in English is simply a combination of used words in Chinese. The Chinese language's capability of saving horizontal and linear space makes this combination feasible to express a new meaning. Three types of constraint arising from limited type and number of Strokes, General Trend toward Simplicity and Square-Framed Space have made their concurrent contribution to the "infertility" of the Chinese word formation. The preference of the Chinese language for new combinations of used words over the creation of total new Chinese words in modern times constitutes a major difference between the formation of English words and the formation of Chinese words in modern times.
\end{abstract}

Index Terms - creation of total new words, general trend toward simplicity, horizontal and linear space, language of "fertility", language of "infertility", new combinations of used words, square-framed space of 方块 字 Fāngkuàizì

\section{INTRODUCTION}

What are major differences between the formation of English words and the formation of Chinese words in modern times? Too many answers might pop up immediately in the Internet. Some of them are related to tenses, gender, sounds, tones, alphabetical letters, strokes, prefix or suffix. However, when we re-read the title of this article, we have to check all the answers very carefully and try to identify whether or not an answer to the question is exclusively related to the essential words "Modern Times" specified in the title. Any differences in terms of tenses, gender, sounds, tones, alphabetical letters and prefix/suffix between these two languages are not only of a modern nature, but they are also an end result of the whole linguistic history.

As far as the formation of new words in modern times is concerned, the Chinese language will be considered as an "infertile" language, whereas the English (as well as other western languages such as French) will be considered as a "fertile" language. The English language is a language of "fertility" due to its continuous formation of new words in modern times. It seems that English will never experience "menopause." As a result, it will never come to the end of its life in "reproductivity". A totally new word which did not previously exist in English or other related languages is often coined such as "robotics" coined by Isaac Asimov (c. January 2, 1920 - April 6, 1992) (Dr. Joseph Koyippally, 2007) and the medicine brand name "Viagra" (Wikipedia, July 2017). However, the Chinese language has undergone a process of "birth control" in the modern times and has become "infertile" in producing totally new words. The recently popularized Chinese character 圆 Jiǒng seems to give an impression of being a totally new Chinese character and find its counterpart * in English in modern times. However, actually it is not a "newborn" Chinese character at all. This character can be traced back to the age of oracle bone inscription where “图 Cōng” "“窗 Chuāng”and “圆 Jiǒng” are mentioned together as “window” (Dictionary of Pictographs, vividict.com, July 2017). 许慎 Xŭ Shèn (58-147), the famous philologist of the Eastern Han Dynasty discussed this word in his 说文解字 Shuō wén jiě zì (Analytical Dictionary of Characters): 圆, 窗牑丽廔, 㬝明也 Jiǒng, chuāng yǒu lì lóu, kăi míng yě (large windows which are exquisitely bright and clear). "Jiong ... is a once obscure Chinese character meaning a 'patterned window'. Since 2008, it has become an internet phenomenon and widely used to express embarrassment and gloom, because of the character's resemblance to a sad facial expression. (Wikipedia, https://en.wikipedia.org/wiki/Jiong, July 2017). The word “圆 Jiǒng" turns out simply to be "an old bottle used for new wine". Only its meaning is changed from "window" to express ideas or feelings such as annoyance, shock, embarrassment. In contrast, the English language experiences its constant "labor pains", continually generating "newborn" words. "Words like gadget, blimp, raunchy, scam, nifty, zit, clobber, boffin, gimmick, jazz and googol have all appeared in the last century or two with no apparent etymology, and are more recent examples of this kind of novel creation of words." (History of English, 
http://www.thehistoryofenglish.com/issues_new.html, July 2017); whereas the Chinese language paradoxically enjoys its pleasure of post-menopausal life and does not have to experience the "labor pain" any more, and the Chinese language learner also does not have to experience the pain in memorizing any totally new Chinese characters. All in all, the Chinese language is "infertile" because nowadays it has almost or totally stopped creating a new word in a similar way the English language has stopped creating any totally new alphabetic letters. In the strictest sense of its meaning, not even one totally new Chinese character has been created since an uncertain date in the modern history just as not even one totally new English alphabetic letter has been generated after the letter "Z").

\section{THE DEFINITION OF THE WORD “MODERN"}

\section{According to Wikipedia,}

Modern history, also referred to as modern period or the modern era, is the historiographical approach to the timeframe after the post-classical era (known as the Middle Ages). [1][2] Modern history can be further broken down into the early modern period and the late modern period after the French Revolution and the Industrial Revolution. Contemporary history is the span of historic events that are immediately relevant to the present time. The modern era began approximately in the 16 th century.

The word "Modern" is a loosely defined concept, delineating a period of time in late history. No one knows exactly when new Chinese characters stopped being created in the Chinese language. This could not have happened too early in Chinese history because much time would have been needed to create a vast and extraordinary number of Chinese characters. In the later age, the Chinese people might have realized that they have created enough or even too many Chinese characters, or they suddenly realized one day that they had found new ways to avoid having to create new characters. Therefore, the word "modern" can be defined here as the period of time when the Chinese language stopped creating its totally new characters.

\section{THE GENERAL TREND}

The general trend in the development of a Chinese character in the Chinese history is moving gradually from simplicity to complexity and then back to simplicity, such as:

the character 左 Zuǒ 'left'（丈甲骨文 Jiăgǔwén 'oracle bone inscription' -> 鹿金文 Jīn wén 'bronze inscription' >后管文 Zhuànwén 'Seal script' ->左 Zuǒ 'left' 标准宋体 Bīäozhǔn sòngť̌ 'Standard SimSun'); (Dictionary of Pictographs, vividict.com, July 2017).

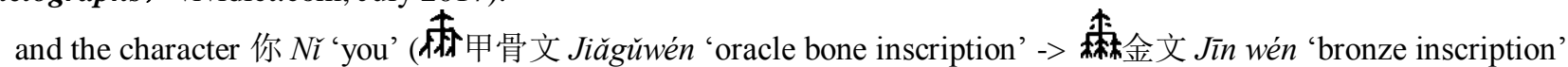
$>$ 爾管文 or sometimes it is moving directly from complexity to simplicity such as:

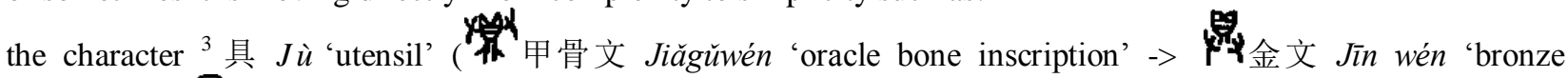
inscription' -> 䝮管文 Dictionary of Pictographs Zhuànwén 'Seal script' -> 具 Jù 标准宋体 Biāozhǔn sòngtǐ 'Standard SimSun' (vividict.com, July 2017).

The transformation from Oracle Inscription to Bronze Script seems a process from a Picture to a kind of "Paraphrase" or to a kind of "translation" from an original language to a target language. More images are added to clarify the meaning of the original picture, and more words are needed to fully translate the original meaning in a picture. Therefore the transformation from Oracle Inscription to Bronze Script is a process from Simple to Complex; for example,

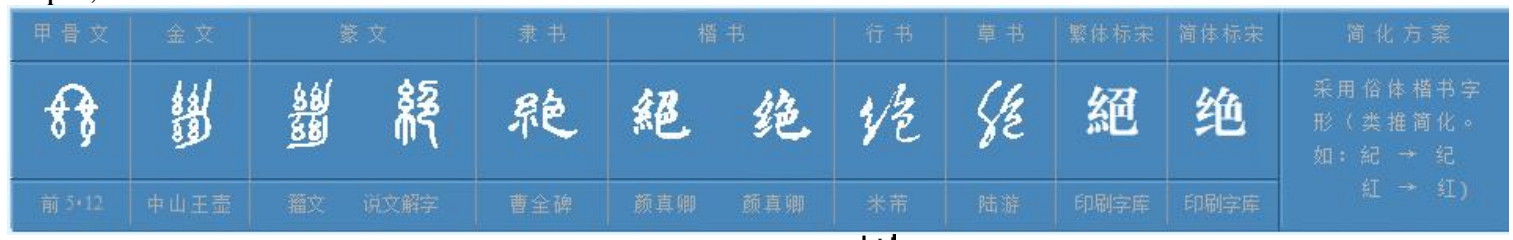

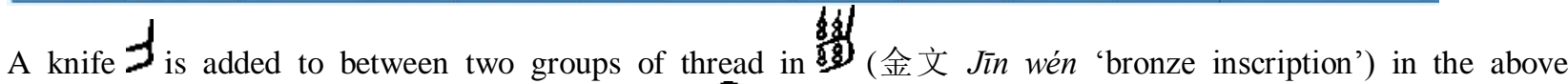
illustration to indicate more clearly than in the picture that a knife is used to cut off threads. More examples of the same kind can be found in the characters 报 Bào 'plead guilty', 神 Shén 'god', 射 Shè 'shoot', etc. (See Dictionary of Pictographs, vividict.com, July 2017) Oracle Bone Inscription and Bronze Script are picture-oriented; Seal Script is partially picture-oriented or partially image-oriented, whereas 隶书 Lìshū 'Official Script' is completely stroke-oriented. Seal Script paved the way for 隶书 Lìshū to complete its stroke-oriented formation of Chinese characters. For example, 


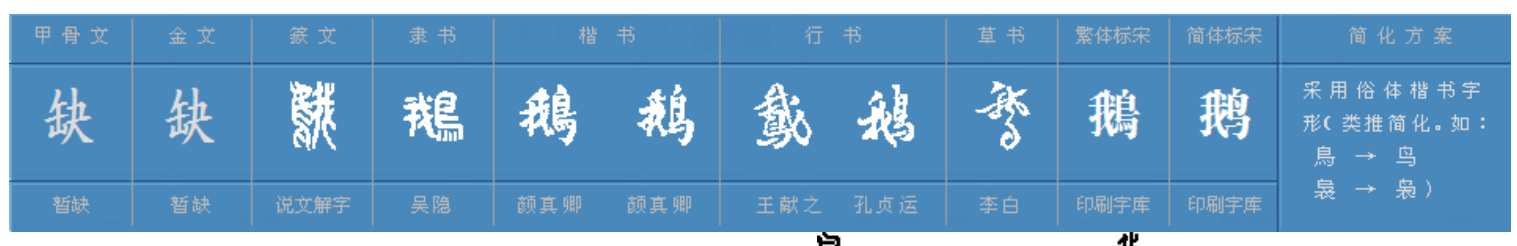

The word 我它 'Goose' in Seal Script is half in an image characters with strokes is first realized in 隶书 Lìshū 'Official Script'. No more hieroglyphs, pictographs or images are allowed to appear in the stroke-oriented Official Script. This transition from Seal Script to Official Script or from image-oriented to stroke-oriented is sometimes so radical and drastic that many changes are often considered by the author of Dictionary of Pictographs as mistakes. Take the Radical 四点底 ... Si diăn dǐ 'four-dot bottom component' for example, it is often used to indicate 火 Huǒ 'fire' as in the Chinese characters 热 rè 'hot', 烈 liè 'intense', 照 zhào 'illuminate', 蒸 zhēng 'steaming', etc. However, this same bottom component is used to indicate 鸟羽 Niăoyú 'bird feathers', 鸟爪 niăozhăo 'birds claw', 鸟尾 niăowěi 'bird tail', 马蹄 mătí 'horseshoe', 鱼尾 yúwěi 'fish tail'. (See

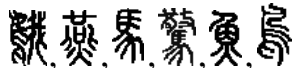

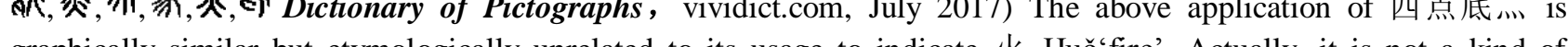
graphically similar but etymologically unrelated to its usage to indicate 火 Huǒ fire’. Actually, it is not a kind of mistake as that author indicates. This application is designed for the sake of simplicity in order to reduce the number of different strokes or to avoid creating another type of stroke. When the transition from picture-oriented or image-oriented to stroke-oriented in 隶书 Lìshu 'Official Script' is so drastic that the picture or image is totally scarified to serve the purpose of simplicity. For example, the image 畸 會 (會 Hui 'rice and dishes were mixed and cooked together' is transformed to a much simpler form $\boldsymbol{由}$ in 會. (For more examples, See 胃 Wèi 'stomach', 思 sī 'thinking' and 果 guǒ 'fruit' (Dictionary of Pictographs, vividict.com, July 2017).

This transition has abandoned complicated forms such as pictures and images and adopted simple forms such as strokes. As a result, it not only has simplified the formation of a word by using strokes but also laid a crucial foundation which later made a concurrent contribution to the "infertility" in the Chinese word formation. The appearance of 简体字 Jiăntǐzi 'Simplified Chinese Characters' which were developed in Mainland China in 1950s seems to serve the function of a birth control surgery and make this general trend to Simplicity irreversible. However, the appearance of computers or cell phones makes this general trend almost stop or makes this movement extremely slow because whether to write a Traditional Chinese Character or a Simplified Chinese Character fundamentally means the same to a keyboard.

\section{IV. 方块字FĀNGKUÀIZì 'SQUARE SCRIPT'}

A Chinese character is also known as 方块字Fāngkuàizi ‘'Square Script or Square-Framed Character or Square Block Word'. After staying away from image-centered Bronze Script and Seal Script, 隶书Lìshū 'Official Script' took the real form of "square word". Each character consists of various strokes formed by different dots or lines as its basic components. There are over 30 different strokes, such as -, I, ) , , ᄀ ᄀ, - , ( ...., large in number, but not countless. Moreover, a Chinese character which can be even composed of two or more single characters within this square space is called合体字Hétǐ zì 'multiple-component character', such as "校Xiào'school' " consisting of "木Mù “wood" and "交Jiāo 'cross'", and "森Sēn 'forest" of three "木Mù". These characters or strokes can be arranged within this square space in a different structure, such as独体结构Dú tǐ jiégòu 'single-character structure', 品字形结构Pìn zìxíng jiégòu 'triangle-character structure', 上下结构Shàngxià jiégòu 'upper and lower character structure', 上中下结构Shàng zhòng xià jiégòu 'upper, middle and lower character structure', 左右结构Zuóyòu jiégòu 'left and right character structure', 左中右结构Zuó zhōng yòu jiégòu 'left, middle and right character structure', 全包围结构Quán bāowéi jiégòu 'allsurrounding character structure', 半包围结构Bàn bāowéi jiégòu 'half-surrounding character structure'. The rearrangement of a combination of these same components or strokes or even characters within this square-frame space had generated many new and different Chinese characters before.

\section{TOTAL Types OF STROKes, GENERAL TREND AND 方块字 'SQUARE SCRIPT'}

Since there are only about or less than 40 different types of strokes available for Chinese characters, this combination and rearrangement of combinations of these strokes are restricted by three types of constraint. First of all, although the rearrangement of a combination of these same components or strokes or even characters could generate many new and different Chinese characters as indicated in the above paragraph, the combination of the limited types of strokes to generate new characters is never endless and is restricted by its own total number of types. At the same time, the same graphical stroke or component is used instead to replace totally different images or shapes in Seal Script and to express totally different meanings in order to avoiding a formation of new types of strokes in 隶书 Lìshū 'Official Script' as

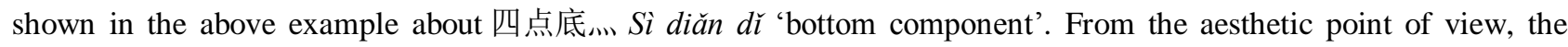
formation of a Chinese character is not simply a random pileup of strokes. The factors such shape, balance, density and 
beauty should also be taken into consideration when developing a new and simple Chinese character. When we increase the number of strokes from one to 12, we will not only see the formation of different Chinese characters in a sequence from 一 $y \bar{\imath}$ 'one', 十 shí 'ten', 木 mù 'wood', 林 lín 'woods' then to 森 sēn 'forest', but also see its limit in forming a new character of more strokes than in 森 sēn 'forest' in this sequence. An addition of one more stroke to the character 森 $s \bar{e} n$ 'forest' in order to form a totally new word in this sequence will distort shape, destroy balance and compromise beauty. Secondly, the potential capability in the combination of these strokes to form simply a new Chinese character is much larger than to form both new and simple characters because the combination of this limited types of strokes to generate both new and simple Chinese characters is considerably restricted by the general trend to reduce strokes in number to form a simple Chinese character. The general trend toward simplicity is irreversible after 简体字 Jiăntǐzi 'Simplified Chinese Characters' has been put into practice. Thirdly, the combination of this limited number of strokes to generate both new and simple Chinese characters is greatly restricted by the square-framed space of 方块字 Fāngkuàizi. The space for each of the Chinese characters of the same font size is same and cannot be expanded. These strokes cannot go beyond this square space to be developed horizontally and linearly like the English language. That means, the number of strokes used within that space is limited and the square-framed space cannot be "over-populated" due to the general trend from Complexity to Simplicity. Although the increase of strokes in number in a character will not increase the size of a Chinese character and will not occupy more space than a character of fewer strokes in Chinese, the general trend is to reduce strokes in number to form a simple Chinese character. If the general trend in the development of a Chinese character is moving toward simplicity, the number of strokes used within that space will be decreased accordingly. When the number of strokes within that space is decreased, the new combination of strokes in forming a totally new character is gradually coming to an end in modern times after over 90,000 Chinese characters have been produced in a history of thousand years.

As a result, the above three types of constraint have led the Chinese language to have abandoned its complicated forms and adopted its simple forms and have made their concurrent contribution to the "infertility" of the Chinese word formation.

\section{NEW WORDS AND New COMBINATION OF USED WORDS}

It is a universal truth that a language is a combination of sentences or words and more. However, it is true to say only to a certain extent that a word is made of a root or a combination of a root with a prefix or suffix because the Chinese language does not have a prefix or suffix in its strictest sense. Therefore, as a Chinese medical student, the first step in learning the medical terms in the Chinese language is not to understand how to divide words into their root, prefix and suffix as a English medical student does.

Comparatively speaking, when learning English, people can read English newspapers after they have learned 3,0004,000 English words, due to the existence of prefixes and suffixes which can help people to expand their vocabulary. However, when learning Chinese, people may at first need more words (at least 5,000-6,000 words or more) to read Chinese newspapers because the Chinese language does not have prefixes and suffixes. But what happens in the later stages of learning is just the opposite: a Chinese language learner may not need to learn too many new words or may not need to learn more new words than an English learner does because the Chinese language in modern times is largely a language of combination of words for the learner in his/her later stages of learning. If a new medical term is needed, Chinese people use the words already known to them and combine them in a new or different order. The English learner on the other hand may need to learn a totally new medical term, such as Viagra, Cialis, jejunum, cancer, etc. This unique and favorable condition for the Chinese language contributes to almost or actually having stopped creating totally new Chinese characters since an uncertain date in the modern history.

As Davi-Ellen Chabner (2011) says, "Studying medical terminology is very similar to learning a new language. At first, the words sound strange and complicated, although they may stand for commonly known disorders and terms. For example, cephalgia means 'headache', and an ophthalmologist is an 'eye doctor"' (P. 3). But for the Chinese learner, his/her first job in learning the language of medicine is just to learn a new combination, even if it is a medical term. The word cephalgia is translated into the Chinese words simply as “头痛 Tóutòng" 'headache' by combining the common words the head “头 Tóu” 'head' with the ache “痛 Tòng” together. It is the same with the word ophthalmologist.

The Chinese language does not have a prefix or suffix in its strictest sense. However, it seems that every Chinese word serves the function of being a prefix or suffix or both of them. What appears in English as a prefix or a suffix will be translated into a word instead in Chinese. For example, the word Electrocardiogram will be translated into “心电图 Xīndiàntú". Here, “心 Xīn” means "heart” for the English "cardio-"; “电 Diàn” means "electro-”; “图 Tû” means "picture" for "-gram." As a Chinese learner, he/she is not really learning a new word such as electrocardiogram but instead combines common words in a new or different order such as “心” (heart), “电” (electricity), and “图” (picture). For an English medical professional, the word "electrocardiogram" is also a combination of a prefix, a combining form (root) and a suffix. However, the name "Viagra" was a totally new term coined even for English medical professionals; the word "Viagra" stands for the name of a medicine and is translated into Chinese as “伟哥 Wěigē". Here, “伟 Wěi" means "great", a very common word in Chinese; “哥 $G \overline{\mathrm{e}}$ ” means "elder brother", another common word in Chinese, 
which is a euphemism here for "penis" among the Chinese community. What is a totally new word in English is simply a combination of used words in Chinese, more often a combination of common or simple words.

Although the English language contains combinations of words such as "goodwill", "schoolboy", "classroom", etc., it is fundamentally a language of alphabetical letters arranged in a horizontal and linear orientation. Only few words of English words will occupy the same horizontal and linear space as Chinese characters. For example, the two-letter English word "OK" will roughly occupy the same horizontal and linear space as the Chinese character “好 Hăo 'OK” of the same font size. However, most of English words occupy more horizontal and linear space than Chinese characters. Therefore, the combination of English words is considerably restricted by its occupying too much horizontal and linear space. You will seldom see a combination of two words that go beyond 15 letters because this will occupy too much space horizontally and, most likely, difficult to pronounce. It is more feasible to create a totally new word instead of creating a new combination of long English words such as "antidisestablishmentarianism" (referred to as the "longest word in English" by Wikipedia). The preference of a new combination of used words to express a new meaning in the Chinese language is justified by the shape of a Chinese character, “方块字 Fāngkuàizi” which is literally translated as "square, block word". Every Chinese character of the same font size takes the shape of a square and occupies the space of the same size. The reader can measure the space which each Chinese character occupies if we use the same font size as in English. The Chinese word “方 Fāng" may take up less horizontal and linear space than an English word of three letters such as “new”. In other words, a combination of three Chinese words such as “方块字 Fāngkuàiz” will take up less space than that of one English word "character" in the same font size. The Chinese language's capability of saving horizontal and linear space in a Chinese character makes the combination of these three Chinese characters 方块字 feasible as a phrase in a horizontally and linear orientation to express a meaning. Thereby, a new combination of Chinese characters in a horizontally and linear orientation can represent a new meaning conveyed by a newly created English word. So, the preference of a new combination of words instead of creating a totally new word to express a new meaning in the Chinese language is predetermined by its square shape, its one-size-fits-all characters, its restricted structure of strokes, its restricted number or types of strokes and its capability of saving horizontal and linear space as well as its general trend to form a simple Chinese character.

\section{CONCLUSION}

Thus, the English learner must memorize "newborn" words produced by a "fertile" language such as English, French, etc.; whereas the Chinese learner paradoxically enjoys memorizing the new combination of used words due to the "dead mechanism" of the Chinese language in producing totally new words. The preference of the Chinese language for new combinations of characters over the creation of total new Chinese characters in modern times becomes a natural result of its development. In this sense, the Chinese language prefers "infertility" to "lifetime productivity" because the Chinese language might find that kind of "lifetime productivity" is a "painful" experience, and unexpectedly, "menopause" becomes a preferred language status in order to avoid such a kind of "pain and suffering" in labor experienced by the English language while creating totally new words. The preference of the Chinese language for new combinations of used words over the creation of total new Chinese words becomes a natural result of its development and constitutes a major difference from the formation of English words in modern times.

\section{REFERENCES}

[1] Chabner, Davi-Ellen. (2011). The Language of Medicine, Ninth Edition. Missouri.

[2] History of English - How New Words Are Created. Retrieved from http://www.thehistoryofenglish.com/issues_new.html, July 2017.

[3] Huang, Fengshan and his team. (1997). English-Chinese Chinese-English Medical Dictionary. Academy Press, Beijing.

[4] Koyippally, Joseph, Dr. (September 2007). Introduction to Linguistics, College of Education, University of Hail. Retrieved from http://haillinguistics.blogspot.ca/2007/11/chapter-7-words-and-word-formation.html, July 2017.

[5] Wikipedia Dictionary, online. Retrieved from https://en.wikipedia.org/wiki/Jiong, July 2017.

[6] Xiàngxíng zìdiăn (Dictionary of Pictographs). Retrieved from vividict.com, July 2017.

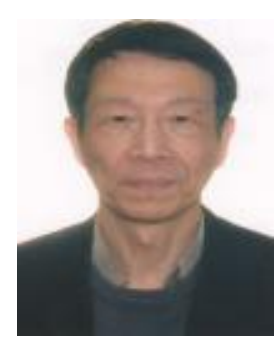

Bianye Li was born in China. He received his Ph.D in Comparative Literature at State University of New York at Binghamton (Binghamton University) in 1998.

He taught Chinese as well as Chinese and Western Literary and Cultural Studies in State of University of New York at Binghamton for two years. Now he is an instructor/professor of Mandarin at George Brown College. He is the translator of the book René Wellek by Martin Bucco and his translation was published by China Social Sciences Publishing House, 1992, Beijing. His book Artificiality in Narrative was published by UMI Dissertation Publishing Services in 1998 online. He is specialized in comparative studies, Mandarin teaching and translation.

Dr. Bianye Li received Teaching Award of Excellence (2007, 2008) from Centennial College and Teaching Award of Excellence (2008) from George Brown College. 